\title{
Assessment of left ventricular diastolic function in children after successful repair of aortic coarctation
}

\author{
Tomasz Florianczyk • Bozena Werner
}

Received: 13 June 2010/ Accepted: 17 December 2010/Published online: 31 December 2010

(C) The Author(s) 2010. This article is published with open access at Springerlink.com

\begin{abstract}
The purpose of the study was an assessment of left ventricular diastolic function in children after the successful repair of aortic coarctation (CoA). The prospective study concerned 32 pediatric patients after the CoA surgery. Tissue Doppler imaging parameters including strain and strain rate and the conventional echocardiographic indexes were analyzed in patients and healthy controls. Analysis of mitral annulus velocities, $E-E^{\prime}$ ratio, strain, and strain rate of left ventricular mid-cavity segments and conventional indexes of mitral inflow showed the worsening of left ventricular diastolic mechanics in the study group compared to healthy controls. The $E / E^{\prime}$ ratio was significantly higher in the study group compared to the control group $(8.30 \pm 3.24$ vs. $6.95 \pm 1.36 ; p<0.05)$. The early diastolic strain rate to late diastolic strain rate ratio as well as early to late diastolic strain ratio of the left ventricular mid-cavity segments were significantly lower in the study group compared to healthy controls $(1.81 \pm 0.63$ vs. $3.74 \pm 1.53 ; p<0.001$ and $1.20 \pm 0.49$ vs. $3.41 \pm 1.26$; $p<0.001)$. No differences of the pulmonary venous flow parameters between those two groups were observed. The left ventricular diastolic mechanics in hypertensive patients after CoA repair did not differ from normotensive subjects. Hypertensive and normotensive children after surgical repair of CoA are found to have worsening of the left ventricular diastolic mechanics suggesting the impairment of the active myocardial relaxation.
\end{abstract}

T. Florianczyk $(\square) \cdot$ B. Werner

Department of Pediatric Cardiology and General Pediatrics,

Medical University of Warsaw, 24 Marszalkowska Street,

00-576 Warsaw, Poland

e-mail: tomasz.florianczyk@wum.edu.pl
Keywords Coarctation of aorta - Diastolic function . TDI $\cdot$ Strain $\cdot$ Strain rate $\cdot$ Children

\section{Introduction}

Invasive measurement of the left ventricular late diastolic pressure is still considered the most accurate method in the diagnosis of left ventricular diastolic dysfunction. Currently echocardiographic examination is the most commonly used method to assess left ventricular diastolic function in routine daily practice [1-4]. Recently, Tissue Doppler imaging (TDI) with analysis of mitral annulus motion velocities is a tool of special significance in evaluation of left ventricular dysfunction in adults [5-9]. Noninvasive diagnostics of the left ventricular diastolic dysfunction in pediatric patients is still based on conventional echocardiographic Doppler parameters. The literature provides few reports on usage of TDI parameters in the assessment of left ventricular diastolic function in children with various pathologies that may lead to diastolic heart failure [10-16].

Worsening of the diastolic function in echocardiographic examination in hypertensive patients is frequently observed before the typical left ventricular concentric hypertrophy [17-19]. The tendency to myocardial remodeling is observed in children after the aortic coarctation repair [20-22]. Therefore, we would like to test the hypothesis that both normotensive and hypertensive children manifest abnormal diastolic mechanics the number of years following successful repair of coarctation of the aorta.

Our prospective study aimed to analyze the left ventricular diastolic function in pediatric subjects in the long follow-up after the successful surgical repair for coarctation of the aorta. 


\section{Patients and methods}

The study protocol was approved by the institutional ethics committee. Informed consent was obtained from the all parents and appropriate adolescents.

The study involved 32 children (including 20 males) after a successful cardiosurgery for aortic coarctation with a mean age of $12.01 \pm 4.24$ years and without any coexistent heart anomaly. A good result of the cardiosurgery was defined as systolic pressure gradient between the right superior and inferior limbs below $20 \mathrm{mmHg}$ measured with a sphygmomanometer and the normal profile of the flow at the aortic isthmus assessed by conventional Doppler imaging.

Patients underwent the repair of aortic coarctation at an average age $3.8 \pm 4.0$ years. Repair was by end-to end anastomosis in 20 patients $(62.5 \%)$ and by subclavian flap in 12 children (37.5\%). The current studies were performed $8.2 \pm 3.3$ years after the surgery. No patients were on antihypertensive medications.

The control group consisted of 34 healthy children (22 and 12 girls) who were matched for the age, body surface area, and mean heart rate with the study group.

The study group was divided into the arterial hypertension subgroup (CoAHT) and the normotensive subgroup (CoANT) based on a standard measurement of blood pressure according to the guidelines set in the fourth report on the diagnosis, evaluation, and treatment of high blood pressure in children and adolescents [23].

Left ventricular mass was determined employing the Devereux formula [24] based on measurements of the left ventricular size in M-mode and presented as an index value adjusted to the body surface area [left ventricular mass index (LVMI)].

The left ventricular diastolic function was analyzed using both TDI and conventional Doppler technique. Conventional Doppler technique included the analysis of the mitral inflow pattern, isovolumic relaxation time (IVRT), and flow in the superior right pulmonary vein.

The following parameters of the mitral inflow pattern were assessed: the maximal velocity of early filling wave $(E)$, the maximal velocity of atrial filling wave $(A), E$ to $A$ velocity ratio $(E / A)$, the time velocity integral of $E$ wave (ETVI), the time velocity integral of A wave (ATVI), $E$ to $A$ TVI ratio (ETVI/ATVI), the $A$ wave duration (DA), the $E$ wave deceleration time calculated as a duration of negative slope of $E$ wave (EDT).

Based on the analysis of the right superior pulmonary vein flow the maximal systolic flow velocity $(S)$, the maximal diastolic flow velocity $(D), S$ to $D$ velocity ratio $(S / D)$, the time velocity integral of $S$ (STVI), the time velocity integral of $D$ wave (DTVI), $S$ to $D$ TVI ratio (STVI/DTVI), the maximal velocity of pulmonary vein atrial reversal flow (Ar), the time velocity integral of Ar wave (ArTVI) and the duration of Ar wave (DAr) were assessed. In addition, the analysis of mitral inflow and pulmonary vein flow patterns allowed for evaluation of the following parameters: DAr to DA ratio (DAr/DA), ArTVI to ATVI ratio (ArTVI/ATVI) and the difference between the duration of $\operatorname{Ar}$ and $A$ waves (DAr - DA).

Evaluation of the left ventricular diastolic function using TDI was based on the velocity of mitral annulus motion and the velocities of mid-cavity segments of septal, lateral, inferior, and anterior left ventricular walls.

Maximal velocities of early and late diastolic mitral annulus motion were analyzed $\left(E^{\prime}\right.$ and $\left.A^{\prime}\right)$ and then $E^{\prime} / A^{\prime}$ ratio was calculated. Moreover, $E^{\prime}$ to $E$ ratio was analyzed. The early and late myocardial diastolic velocities for the mid-cavity segments of septal left ventricular wall $\left(\mathrm{SWE}^{\prime}\right.$ and SWA $^{\prime}$ ) were evaluated like demonstrated in the Fig. 1. Subsequently $\mathrm{SWE}^{\prime} / \mathrm{SWA}^{\prime}$ ratio was calculated. The analysis of myocardial diastolic velocities for the mid-cavity segments of lateral, inferior, and anterior left ventricular walls were performed the same way. The final results of the myocardial diastolic velocities of the mid-cavity segments were presented as arithmetic means of $E^{\prime}, A^{\prime}$ and $E^{\prime} / A^{\prime}$ ratio, respectively, for the mid-cavity segments of the septal, lateral, inferior, and anterior walls of the left ventricle.

Echocardiographic scans in the form of five consecutive beat loops for the analysis of strain and strain rate were acquired using TDI with color-coding at a maximal available in individual patients frame rate (minimum $90 \mathrm{~Hz}$ ) and simultaneous ECG monitoring. All of the patients were in sinus rhythm in ECG. Subsequently, the analysis applied Q-LAB feature based on an averaged curves of five consecutive beats like demonstrated in Fig. 2. Global strain rate (SR) and strain $(\varepsilon)$ values for the mid-cavity segments of the left ventricle in early and late diastole were determined as arithmetic means of strain and strain rate, respectively, for the mid-cavity segments of the septal, lateral, inferior and anterior walls of the left ventricle. The following parameters of the global longitudinal strain rate and strain were analyzed: the early diastolic strain rate and strain (ESR and $\mathrm{E} \varepsilon$ ), the late diastolic strain rate and strain (ASR and $\mathrm{A} \varepsilon$ ), $\mathrm{ESR}-\mathrm{ASR}$ ratio and $\mathrm{E} \varepsilon-\mathrm{A} \varepsilon$ ratio.

Continuous variables were expressed as mean values and standard deviations. Differences between groups were compared using Student $t$ test for independent groups and $U$ Mann-Whitney test when the distribution of the variable was asymmetrical. Statistical significance was set at a probability value $<0.05$.

\section{Results}

Mean systolic blood pressure in the study group was significantly higher than in the controls $(112.4 \pm 12.9$ vs. 
Fig. 1 The early $\left(\mathrm{SWE}^{\prime}\right)$ and late (SWA') myocardial diastolic velocities for the midcavity segments of septal left ventricular wall. The analysis of myocardial diastolic velocities for the mid-cavity segments of lateral, inferior and anterior left ventricular walls were performed the same way

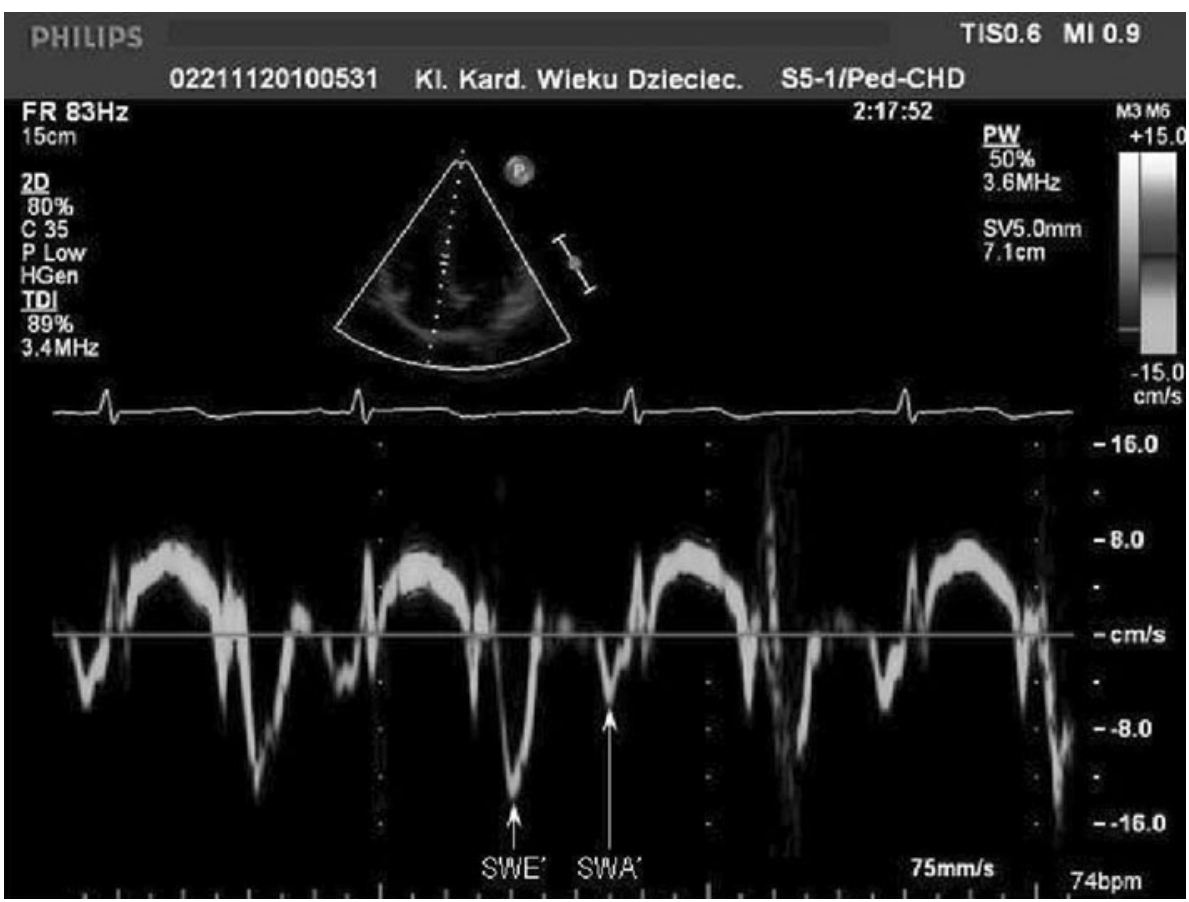

$103.7 \pm 10.6 \mathrm{mmHg} ; \quad p<0.01)$, while diastolic blood pressure in those groups remained non-different $(59.9 \pm$ 7.3 vs. $58.9 \pm 6.5 \mathrm{mmHg} ; p>0.05) ; 8$ children $(25.0 \%)$ with arterial hypertension were included into the CoAHT group and the remaining 24 normotensive ones (75.0\%) into the CoANT group.

The left ventricular mass index was significantly higher in the study group compared to control group (52.4 \pm 9.4 vs. $\left.72.8 \pm 12.9 \mathrm{~g} / \mathrm{m}^{2} ; p<0.001\right)$. However, no significant differences in LVMI were found between CoAHT and CoANT subgroups (73.6 \pm 16.1 vs. $72.6 \pm 12.0 ; p>0.05$ ).

The results of conventional echocardiographic parameters are presented in Fig. 3. The statistical comparisons of the time velocity integrals of $E, A, S, D$, Ar behaved like respective maximal velocities. There were significant differences in the Doppler mitral inflow variables between the study group and the control group suggesting the left ventricular abnormal diastolic mechanics in children after the aortic coarctation repair. No differences between those groups were observed in the pulmonary venous flow indices. Statistical analysis revealed no significant differences of all conventional Doppler parameters between our population of hypertensive and normotensive children after the CoA surgical treatment.

The results of diastolic function assessment using mitral annulus motion, myocardial velocities, strain, and strain rate parameters are depicted in Table 1 . There were significant differences documented in the mean values of velocity of mitral annulus motion, global velocities of midcavity segments as well as the global strain rate and strain for the mid-cavity segments of the left ventricle between the study and control groups. The statistical differences regarding TDI parameters between hypertensive and normotensive patients after previous repair of $\mathrm{CoA}$ were not significant.

The $E / E^{\prime}$ ratio was significantly higher in the study group compared to the control group $(8.3 \pm 3.2$ vs. $6.9 \pm 1.4$; $p<0.05)$. This parameter did not differ between hypertensive and normotensive patients after the CoA surgical treatment $(8.4 \pm 3.9$ vs. $8.2 \pm 3.1 ; p>0.05)$.

\section{Discussion}

Arterial hypertension is often found in children the number of years following successful repair of the coarctation of the aorta in childhood. The incidence of arterial hypertension in this population ranges up to $75 \%$ depending on the age at the age at the time of repair and follow-up period $[20,22]$. The systolic arterial hypertension and the exercise-induced hypertension are the leading problems. In our study, systolic arterial hypertension was found in $8(25 \%)$ out of 32 children after the aortic coarctation repair. Progressive interstitial fibrosis could play a major role in the pathogenesis of left ventricular diastolic dysfunction in those patients. This pathology, along with thickening of the myocardial walls, increases ventricular rigidity compromising the stretching capability of the myofibrils. An increased proliferation of fibroblasts and the resulting influence on collagen synthesis plays a key role in this 


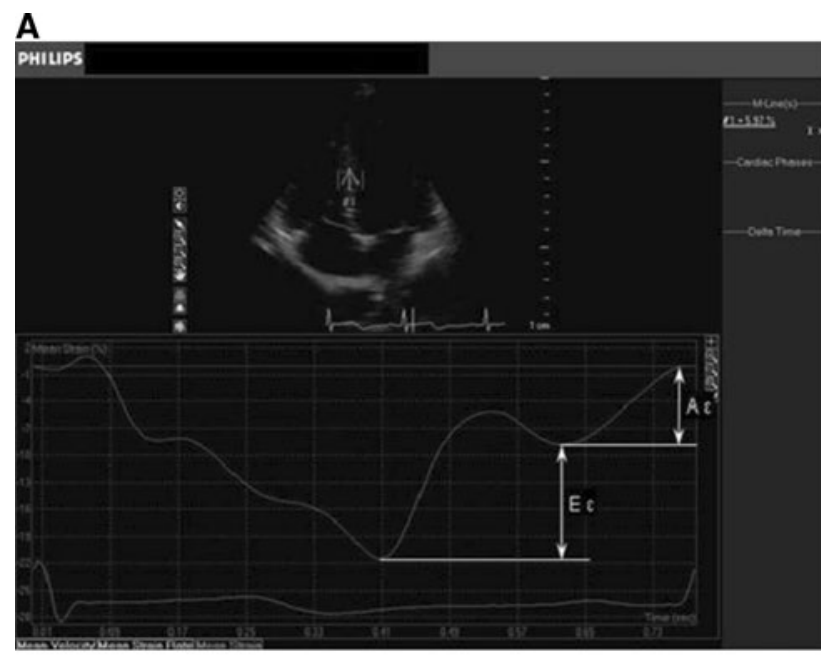

B

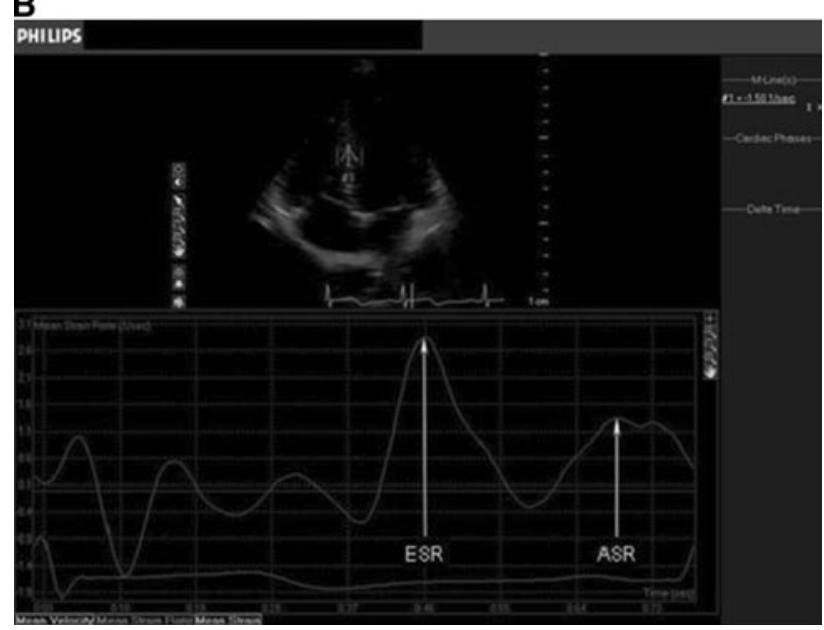

Fig. 2 Curves of strain (a) and strain rate (b) analyzed using Q-LAB application of mid-cavity segment of left ventricular septal wall. Quantification of strain and strain rate parameters of mid-cavity segments of lateral, inferior and anterior left ventricular wall were performed similarly. $E \varepsilon$ the early diastolic strain, $A \varepsilon$ the late diastolic strain, ESR the early diastolic strain rate, ASR the late diastolic strain rate

process $[25,26]$. Ultimately, this leads to the elevation of ventricular filling pressure disproportionate to the ventricular volume.

The results of our study employing conventional Doppler mode echocardiography revealed the abnormal left ventricular diastolic mechanics (evidenced by decrease in the maximal velocity of early filling wave and time velocity integral of $E$ wave, increase of maximal velocity and time velocity integral of $A$ wave, and decrease in $E / A$ and EVTI/AVTI ratios in patients after surgical repair of CoA) as compared to the healthy children. In addition, significantly lower $\mathrm{E}$ wave deceleration time and prolongation of the left ventricular IVRT were observed in children from the study group compared to the control group.

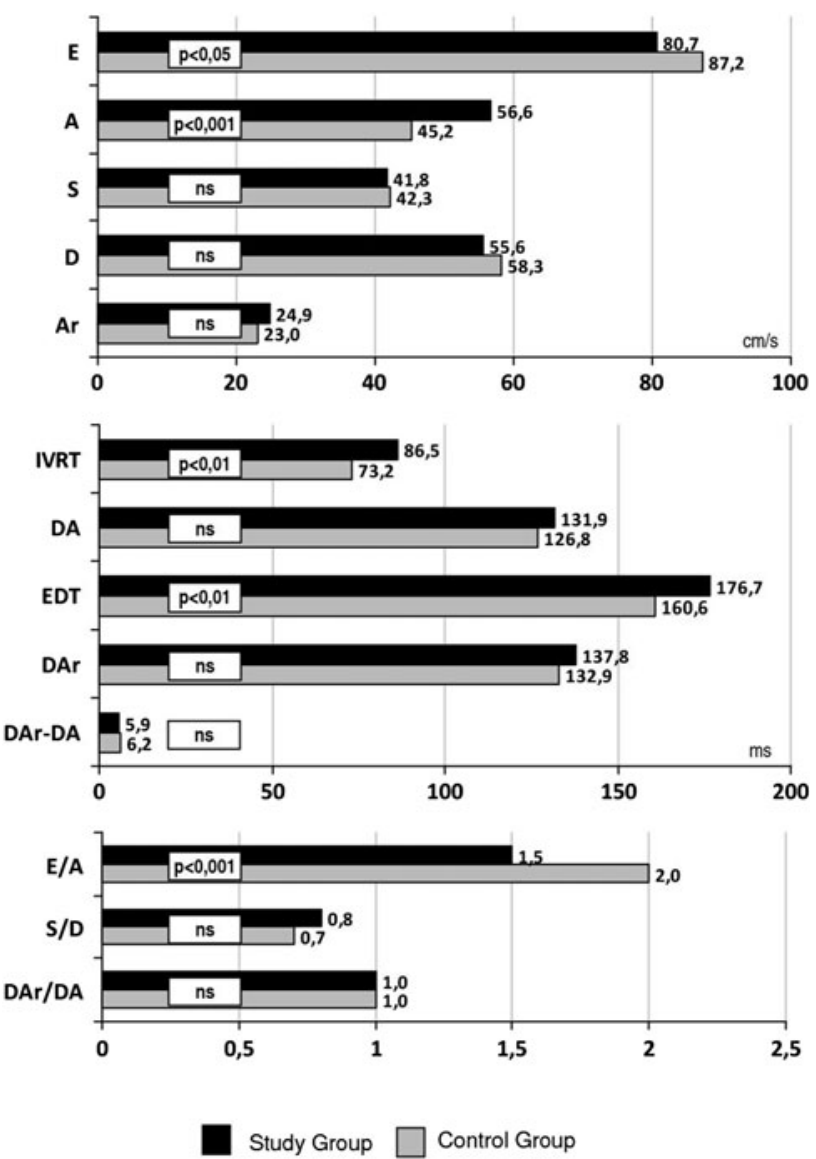

Fig. 3 The results of conventional Doppler parameters in the study group and control group (a) and in the CoAHT and CoANT subgroups (b). $E$ the maximal velocity of early filling wave of the mitral inflow, $A$ the maximal velocity of atrial filling wave of the mitral inflow, $S$ the maximal systolic flow velocity in the right superior pulmonary vein, $D$ the maximal diastolic flow velocity in the right superior pulmonary vein, $A r$ the maximal velocity of atrial reversal flow in the right superior pulmonary vein, IVRT isovolumic relaxation time, $D A$ the $A$ wave duration, $E D T$ the $E$ wave deceleration time, $D A r$ the $A r$ wave duration, $D A r-D A$ the difference between the duration of $\mathrm{Ar}$ and $A$ waves, $n s$ not significant

Currently there are discrepancies in the findings of research trials using conventional Doppler echocardiography for the evaluation of diastolic function in patients after repair of CoA. Moskowitz et al. [27] found significantly lower $E / A$ ratio in patients after repair of $\mathrm{CoA}$ than in healthy children. Leandro et al. [28] reported higher maximal velocity of $A$ wave and lower $E / A$ ratio in patients with the history of CoA compared to healthy children. Yet, no significant differences were documented for the time velocity integral of early mitral inflow wave or the maximal velocity of $A$ wave and EVTI/AVTI ratio. However, on the contrary the analysis of mitral inflow profile by Trojnarska et al. [22] showed no abnormality of left ventricular diastolic mechanics in adults after the repair of CoA. 
Table 1 Results of mitral annulus motion, strain and strain rate parameters in the study group, control group and the CoAHT and CoANT subgroups

\begin{tabular}{lrrrr}
\hline & Study group & \multicolumn{1}{l}{$\begin{array}{l}\text { Control } \\
\text { Group }\end{array}$} & \multicolumn{1}{l}{ CoAHT } & \multicolumn{1}{l}{ CoANT } \\
\hline$E^{\prime}(\mathrm{cm} / \mathrm{s})$ & $-10.5 \pm 2.8^{\#}$ & $-12.7 \pm 2.3$ & $-10.5 \pm 3.0$ & $-10.9 \pm 2.7$ \\
$A^{\prime}(\mathrm{cm} / \mathrm{s})$ & $-6.4 \pm 1.4$ & $-6.3 \pm 1.2$ & $-6.4 \pm 1.5$ & $-6.4 \pm 1.3$ \\
$E^{\prime} / A^{\prime}$ & $1.7 \pm 0.6^{\#}$ & $2.1 \pm 0.4$ & $1.7 \pm 0.7$ & $1.7 \pm 0.6$ \\
$\mathrm{MVE}^{\prime}(\mathrm{cm} / \mathrm{s})$ & $-10.6 \pm 2.7^{\#}$ & $-13.4 \pm 3.1$ & $-10.5 \pm 3.2$ & $-10.9 \pm 2.6$ \\
$\mathrm{MVA}^{\prime}(\mathrm{cm} / \mathrm{s})$ & $-4.4 \pm 1.2$ & $-4.5 \pm 1.2$ & $-4.3 \pm 1.5$ & $-4.4 \pm 1.1$ \\
$\mathrm{MVE}^{\prime} / \mathrm{MVA}^{\prime}$ & $2.6 \pm 1.0^{\#}$ & $3.1 \pm 0.9$ & $2.5 \pm 1.2$ & $2.6 \pm 0.9$ \\
$\mathrm{ESR}\left(\mathrm{s}^{-1}\right)$ & $3.0 \pm 0.6^{\#}$ & $3.6 \pm 0.9$ & $2.9 \pm 0.7$ & $3.1 \pm 0.5$ \\
$\mathrm{ASR}\left(\mathrm{s}^{-1}\right)$ & $1.9 \pm 0.5^{\#}$ & $1.3 \pm 0.5$ & $2.0 \pm 0.7$ & $1.9 \pm 0.5$ \\
$\mathrm{ESR} / \mathrm{ASR}$ & $1.8 \pm 0.6^{\#}$ & $3.7 \pm 1.5$ & $1.8 \pm 0.7$ & $1.8 \pm 0.6$ \\
$\mathrm{E} \varepsilon(\%)$ & $14.0 \pm 3.0^{*}$ & $16.5 \pm 5.2$ & $14.0 \pm 3.4$ & $14.2 \pm 2.9$ \\
$\mathrm{~A} \varepsilon(\%)$ & $14.4 \pm 4.9 \#$ & $5.9 \pm 1.6$ & $14.5 \pm 5.0$ & $14.4 \pm 4.9$ \\
$\mathrm{E} \varepsilon / \mathrm{A} \varepsilon$ & $1.2 \pm 0.5^{\#}$ & $3.4 \pm 1.3$ & $1.2 \pm 0.6$ & $1.3 \pm 0.5$ \\
\hline
\end{tabular}

CoAHT hypertensive patients after the aortic coarctation repair, CoANT normotensive patients after the aortic coarctation repair, $E^{\prime}$ the maximal velocity of early diastolic mitral annulus motion, $A^{\prime}$ the maximal late diastolic velocity of mitral annulus motion, $M V E$ the early global diastolic myocardial velocity for left ventricular mid-cavity segments, $M V A$ the late global diastolic myocardial velocity for left ventricular mid-cavity segments, ESR the early global left ventricular diastolic strain rate, ASR the late global left ventricular diastolic strain rate, $E \varepsilon$ the early global left ventricular diastolic strain, $A \varepsilon$ the late global left ventricular diastolic strain

\# $p<0.001$ compared to the control group

$* p<0.05$ compared to the control group

In our study, a disturbed mitral inflow with normal pulmonary venous flow were found. These results would rather suggest the impairment of left ventricular relaxation than abnormality of compliance.

Our TDI based results confirmed the presence of abnormal left ventricular diastolic mechanics in children after surgical repair of CoA. Significantly lower maximal velocity of the early diastolic mitral annulus motion and early diastolic velocities of mid-cavity segments of septal, lateral, inferior, and anterior left ventricular walls were found in the study group in comparison with the same parameters in healthy children. Moreover, children undergoing repair of CoA in the past were observed to have significantly lower maximal early-to-late diastolic velocity of mitral annulus motion ratio as well as early-to-late diastolic velocities of mid-cavity segments of septal, lateral, inferior, and anterior left ventricular walls ratios. Evaluation of $E / E^{\prime}$ ratio in our study showed significantly higher values of this parameter in study group than in control group. Analysis of strain parameters in mid-cavity segments of the left ventricle showed significantly lower early diastolic strain, higher late diastolic strain and a decrease in $\mathrm{E} \varepsilon / \mathrm{A} \varepsilon$ ratio when compared to the control group. The analogous differences were found based on strain rate in the mid-cavity segments of the left ventricular walls.
The literature provides few reports on left ventricular diastolic function measured by means of TDI in children. Di Salvo et al. [11] observed significantly higher $E / E^{\prime}$ ratio and deceleration time of $E$ wave in normotensive pediatric patients after surgical repair of CoA than in the age-matched healthy subjects. The same authors, as opposed to our findings, reported prolongation of the mitral $A$ wave duration with concurrent lack of significant difference of the $E / A$ ratio between the studied groups. Lam et al. [29] claimed a significant decrease in maximal velocity of early diastolic mitral annulus motion and an increase of $E / E^{\prime}$ ratio in adults after surgical repair of CoA versus control group. In adults, the $E / E^{\prime}$ ratio, among all echocardiographic left ventricular diastolic indexes, presents the highest correlation with left ventricular end-diastolic pressure and some authors use this parameter to stratify the risk of clinical manifestation of left ventricular failure [6, 30-36]. The data concerning $E / E^{\prime}$ ratio in children is not extensive and the detailed value of this parameter, which indicates the left ventricular diastolic dysfunction has not been determined yet. However, McMahon et al. [13] found the $E / E^{\prime}$ ratio as a promising predictor of cardiac arrest and ventricular tachycardia in children with hypertrophic cardiomyopathy.

Our study evaluated left ventricular diastolic function using strain and strain rate. Both of these parameters reflect local myocardial abnormalities therefore we used average values calculated from mid-cavity segments of septal, lateral, anterior, and inferior left ventricular walls. Currently there is no common recommendation how to estimate global left ventricular diastolic function with strain and strain rate parameters. Kim et al. [37] estimated global left ventricular diastolic function using the average value obtained in the basal, mid-cavity and apical segments of septal, lateral, anterior, and inferior walls. However, we did not find any previous study reporting left ventricular diastolic function evaluation with strain and strain rate specifically in children.

Our study did not provide evidence of significant differences between the subgroup of hypertensive and normotensive children after repair of $\mathrm{CoA}$ with respect to left ventricular diastolic function based on the analysis of standard echocardiographic parameters as well as TDI. The left ventricular diastolic dysfunction in hypertensive patients is mainly observed in subjects with concentric hypertrophy. In our study, we observed the impairment of left ventricular diastolic function in children with history of repair of $\mathrm{CoA}$ versus healthy children most likely results from increased left ventricular muscle mass maintained after the repair despite good outcomes of the cardiac surgery. Left ventricular mass index showed no significant differences between hypertensive and normotensive patients after the CoA repair. It may suggest that worsening 
of the left ventricular diastolic mechanics in patients after the CoA surgery is not only the result of arterial hypertension. It could be a consequence of the too old age at the time of surgery. Contemporary these patients are qualified to the elective surgical treatment mostly in the second year of age.

Published data proved that aortic coarctation is not only a local anatomical pathology of the aortic isthmus but is associated with the persistent abnormalities of systemic precoarctational arterial function due to fibrosis and necrosis of the medial layer of arterial walls which leads to increased arterial stiffness and impaired reactivity [38-40]. Further research on left ventricular diastolic function in these patients over the longer postoperative period would be reasonable.

\section{Conclusions}

1. Hypertensive as well as normotensive children after surgical repair of coarctation of the aorta are found to have worsening of the left ventricular diastolic mechanics.

2. Left ventricular diastolic dysfunction in subjects after surgical repair of coarctation of the aorta suggests the impairment of the myocardial relaxation.

\section{Study limitations}

The lack of significant statistical differences of echocardiographic parameters between the hypertensive and normotensive patients may be due to the small sample size.

Open Access This article is distributed under the terms of the Creative Commons Attribution Noncommercial License which permits any noncommercial use, distribution, and reproduction in any medium, provided the original author(s) and source are credited.

\section{References}

1. Galderisi M (2005) Diastolic dysfunction and diastolic heart failure: diagnostic, prognostic and therapeutic aspects. Cardiovasc Ultrasound 3:9. doi:10.1186/1476-7120-3-9

2. Bursi F, Weston SA, Redfield MM, Jacobsen SJ, Pakhomov S, Nkomo VT, Meverden RA, Roger VL (2006) Systolic and diastolic heart failure in the community. JAMA 296:2209-2216

3. Swedberg K, Cleland J, Dargie H, Drexler H, Follath F, Komajda M, Tavazzi L, Smiseth OA, The Task Force For The Diagnosis, Treatment Of Chronic Heart Failure of the European Society of Cardiology (2005) Guidelines for the diagnosis and treatment of chronic heart failure: executive summary (update 2005). Eur Heart J 26:1115-1140. doi:10.1093/eurheartj/ehi204

4. Gorelik O, Almoznino-Sarafian D, Shteinshnaider M, Alon I, Tzur I, Sokolsky I, Efrati S, Babakin Z, Modai D, Cohen N
(2009) Clinical variables affecting survival in patients with decompensated diastolic versus systolic heart failure. Clin Res Cardiol 98:224-232. doi:10.1007/s00392-009-0746-1

5. Arques S (2009) Rationale for a widespread use of the spectral tissue Doppler-derived $E / E^{\prime}$ despite its failure to closely predict invasively measured left ventricular diastolic pressure. Int J Cardiol 12:139-140. doi:10.1016/j.ijcard.2008.01.051

6. Bruch C, Grude M, Muller J, Breithardt G, Wichter T (2005) Usefulness of tissue Doppler imaging for estimation of left ventricular filling pressures in patients with systolic and diastolic heart failure. Am J Cardiol 95:892-895. doi:10.1016/j.amjcard. 2004.12.017

7. Gottdiener JS, Bednarz J, Devereux R, Gardin J, Klein A, Manning WJ, Morehead A, Kitzman D, Oh J, Quinones M, Schiller NB, Stein JH, Weissman NJ, American Society of Echocardiography (2004) American Society of Echocardiography recommendations for use of echocardiography in clinical trials. J Am Soc Echocardiogr 17:1086-1119

8. Sohn D-W, Chai I-H, Lee D-J, Kim HC, Kim HS, Oh BH, Lee MM, Park YB, Choi YS, Seo JD, Lee YW (1997) Assessment of mitral annulus velocity by Doppler tissue imaging in the evaluation of left ventricular diastolic function. J Am Coll Cardiol 30:474-480

9. Butz T, Piper C, Langer C, Wiemer M, Kottmann T, Meissner A, Plehn G, Trappe HJ, Horstkotte D, Faber L (2010) Diagnostic superiority of a combined assessment of the systolic and early diastolic mitral annular velocities by tissue Doppler imaging for the differentiation of restrictive cardiomyopathy from constrictive pericarditis. Clin Res Cardiol 99:207-215. doi:10.1007/s00392009-0106-1

10. Baysal T, Peru H, Oran B, Sahin TK, Koksal Y, Karaaslan S (2009) Left ventricular diastolic function evaluated with tissue Doppler imaging in children with familial Mediterranean fever. Clin Rheumatol 28(1):23-28. doi:10.1007/s10067-008-0976-z

11. Di Salvo G, Pacileo G, Limongelli G, Verrengia M, Rea A, Santoro G, Gala S, Castaldi B, D’Andrea C, Caso P, Giovanna Russo M, Calabro R (2007) Abnormal regional myocardial deformation properties and increased aortic stiffness in normotensive patients with aortic coarctation despite successful correction: an ABPM, standard echocardiography and strain rate imaging study. Clin Sci 113:259-266. doi:10.1042/CS20070085

12. Fazio G, Pipitone S, Iacona MA, Marchi S, Mongiovi M, Zito R, Sutera L, Novo G, Novo S (2007) Evaluation of diastolic function by the tissue Doppler in children affected by non-compaction. Int J Cardiol 116(2):e60-e62. doi:10.1016/j.ijcard.2006.07.205

13. McMahon CJ, Nagueh SF, Pignatelli RH, Denfield SW, Dreyer WJ, Price JF, Clunie S, Bezold LI, Hays AL, Towbin JA, Eidem BW (2004) Characterization of left ventricular diastolic function by tissue Doppler imaging and clinical status in children with hypertrophic cardiomyopathy. Circulation 109(14):1756-1762. doi: 10.1161/01.CIR.0000124723.16433.31

14. Mohammed A, Mertens L, Friedberg MK (2009) Relations between systolic and diastolic function in children with dilated and hypertrophic cardiomyopathy as assessed by tissue Doppler imaging. J Am Soc Echocardiogr 22(2):145-151. doi:10.1016/ j.echo.2008.11.010

15. Rumeau P, Acar P, Paranon S, Bassil R, Cournot M, Dulac Y, Guitton J, Latcu G (2007) Evaluation of left ventricular diastolic function in children by Doppler tissue imaging. Arch Mal Coeur Vaiss 100(5):405-410

16. Saygili A, Yildirim SV, Cengiz N, Uslu Y, Tokel K, Saatçi U (2005) Assessment of left ventricular diastolic function by Doppler tissue imaging in children with end-stage renal disease. Acta Paediatr 94(8):1055-1059. doi:10.1080/08035250510025798

17. Aurigemma G, Gottdiener J, Schemanski L, Gardin J, Kitzman D (2001) Predictive value of systolic and diastolic function for 
incident congestive heart failure in the elderly: the cardiovascular health study. J Am Coll Cardiol 37:1042-1048

18. Poulsen S, Andresen N, Ivarsen P, Mogensen CE, Egeblad H (2003) Doppler tissue imaging reveals systolic dysfunction in patients with hypertension and apparent "isolated" diastolic dysfunction. J Am Soc Echocardiogr 16:724-731. doi:10.1016/ S0894-7317(03)00403-6

19. Schillaci G, Pasqualini L, Verdecchia P, Vaudo G, Marchesi S, Porcellati C, de Simone G, Mannarino E (2002) Prognostic significance of left ventricular diastolic dysfunction in essential hypertension. J Am Coll Cardiol 39:2005-2011

20. De Divitiis M, Pilla C, Kattenhorn M, Donald A, Zadinello M, Wallace S, Redington A, Deanfield J (2003) Ambulatory blood pressure, left ventricular mass, and conduit artery function late after successful repair of coarctation of the aorta. J Am Coll Cardioll 41:2259-2265. doi:10.1016/S0735-1097(03)00480-7

21. O'Sullivan JJ, Derrick G, Darnell R (2002) Prevalence of hypertension in children after early repair of coarctation of the aorta: a cohort study using casual and 24 hour blood pressure measurement. Heart 88:163-166. doi:10.1136/heart.88.2.163

22. Trojnarska O, Szyszka A, Ochotny R, Siwinska A, Cieslinski A (2003) Blood pressure, left ventricular mass and function in adult patients after the successful repair of coarctation of the aorta. Kardiol Pol 59:316-317

23. National high blood pressure education program working group on high blood pressure in children, adolescents (2004) The fourth report on the diagnosis, evaluation and treatment of high blood pressure in children and adolescents. Pediatrics 114:555-576

24. Devereux RB, Alonso D, Lutas EM, Gottlieb GJ, Campo E, Sachs I, Reichek N (1986) Echocardiographic assessment of left ventricular hypertrophy: comparison to necropsy findings. Am J Cardiol 57: 450-455

25. Fouad-Tarazi FM (1990) Ventricular diastolic function of the heart in systemic hypertension. Am J Cardiol 65:85G-88G

26. Moreo A, Ambrosio G, De Chiara B, Pu M, Tran T, Mauri F, Raman SV (2009) Influence of myocardial fibrosis on left ventricular diastolic function. Circ Cardiovasc Imaging 2:437-443. doi:10.1161/CIRCIMAGING.108.838367

27. Moskowitz WB, Schieken RM, Mosteller M, Bossano R (1990) Altered systolic and diastolic function in children after "successful" repair of coarctation of the aorta. Am Heart J 120:103

28. Leandro J, Smallhorn JF, Benson L, Musewe N, Balfe JW, Dyck JD, West L, Freedom R (1992) Ambulatory blood pressure monitoring and left ventricular mass and function after the successful repair of coarctation of the aorta. J Am Coll Cardiol 20: 197-204

29. Lam Y-Y, Kaya MG, Li W, Mahadevan VS, Khan AA, Henein MY, Mullen M (2007) Effect of endovascular stenting of aortic coarctation on biventricular function in adults. Heart 93:1441-1447. doi: 10.1136/hrt.2006.106377

30. Hunt SA, Abraham WT, Chin MH (2005) ACC/AHA 2005 Guideline Update for the Diagnosis and Management of Chronic Heart Failure in the Adult: a report of the American College of Cardiology/American Heart Association Task Force on Practice Guidelines (Writing Committee to Update the 2001 Guidelines for the Evaluation and Management of Heart Failure): developed in collaboration with the American College of Chest Physician and the International Society for Heart and Lung Transplantation: endorsed by the Heart Rhythm Society. Circulation 112:e154e235. doi:10.1161/CIRCULATIONAHA.105.167586

31. Arques S, Roux E, Lucioni R (2007) Current clinical applications of spectral tissue Doppler echocardiography $\left(E / E^{\prime}\right.$ ratio) as a noninvasive surrogate for left ventricular diastolic pressures in the diagnosis of heart failure with preserved left ventricular systolic function. Cardiovasc Ultrasound 5:16-27. doi:10.1186/ 1476-7120-5-16

32. Hirata K, Hyodo E, Hozumi T, Kita R, Hirose M, Sakanoue Y, Nishida Y, Kawarabayashi T, Yoshiyama M, Yoshikawa J, Akasaka T (2009) Usefulness of the combination of systolic function by left ventricular ejection fraction and diastolic function by $E / E^{\prime}$ to predict prognosis in patients with heart failure. Am J Cardiol 103:1275-1279. doi:10.1016/j.amjcard.2009.01.024

33. Hummel YM, Klip ITJ, de Jong RM, Pieper PG, van Veldhuisen DJ, Voors AA (2010) Diastolic function measurements and diagnostic consequences: a comparison of pulsed wave- and color coded tissue Doppler imaging. Clin Res Cardiol. doi:10.1007/s00392010-0141-y

34. Triantafyllou KA, Karabinos E, Kalkandi H, Kranidis AI, Babalis D (2009) Clinical implications of the echocardiographic assessment of left ventricular long axis function. Clin Res Cardiol 98:521-532. doi: 10.1007/s00392-009-0046-9

35. Weidemann F, Strotmann JM (2008) Use of tissue Doppler imaging to identify and manage systemic diseases. Clin Res Cardiol 97:65-73. doi:10.1007/s00392-007-0566-0

36. Kamp O, Metra M, De Keulenaer GW, Pieske B, Conraads V, Zamorano J, Huysse L, Vardas PE, Bőhm M, Dei Cas L (2010) Effect of the long-term administration of nebivolol on clinical symptoms, exercise capacity and left ventricular function in patients with heart failure and preserved left ventricular ejection fraction: background, aims and design of the ELANDD study. Clin Res Cardiol 99:75-82. doi:10.1007/s00392-009-0098-x

37. Kim H, Cho H-O, Cho Y-K, Nam C-W, Han S-W, Hur S-H, Kim K-S, Kim Y-N, Kim K-B (2008) Relationship between early diastolic strain rate imaging and left ventricular geometric pattern in hypertensive patients. Heart Vessels 23:271-278. doi:10.1007/ s00380-008-1042-0

38. De Divitiis M, Pilla C, Kattenhorn M, Zadinello M, Donald A, Leeson P, Wallace S, Redongton A, Deanfield JE (2001) Vascular dysfunction after repair of coarctation of the aorta: impact of early surgery. Circulation 104(suppl I):I165-I170. doi:10.1161/ hc $37 \mathrm{t} 1.094900$

39. Niva K, Perloff JK, Bhuta SM, Laks H, Drinkwater DC, Child JS, Miner PD (2001) Structural abnormalities of great arterial walls in congenital heart disease: light and electron microscopic analyses. Circulation 103:393-400

40. Vogt M, Kühn MD, Baumgartner D, Baumgartner C, Busch R, Kostolny M, Hess J (2005) Impaired elastic properties of the ascending aorta in newborns before and early successful coarctation repair. Circulation 111:3269-3273. doi:10.1161/ CIRCULATIONAHA.104.529792 